\title{
1959 Institute for California Judges- Panel Discussion Part III: Instructing the Jury
}

Presented as part of the program of the Institute for California Judges under the sponsorship of the Conference of California Judges and the School of Law, University of California, Berkeley, June 15-17, 1959, in the Moot Court Room, School of Law, University of California, Berkeley. Participants:

The Honorable Raymond E. Peters, Justice of the Supreme Court of California

The Honorable Willtam T. Sweigert, Judge of the Superior Court, San Francisco County

C. Ray Robinson, Attorney at Law, Merced and San Francisco, California

Davm W. LouIseli, Professor of Law, School of Law, University of California, Berkeley

The panel commenced with an opening statement by each member, followed by questions from the panel to one another and from the floor.

JUSTICE PETERS: I am permitted to state on behalf of this panel that all of its members are sold on the jury system. As you know, considerable attacks on the jury system - some from very high places-have been made; there have been proposals and attempts to set up administrative boards or panels of judges to hear specialized types of cases. We are all convinced that the jury system is the best system of determining the facts that has yet been devised by the legal profession. It is necessary, however, that the jury system be improved and modernized and made to fit the needs of the twentieth century. Great strides have been taken, in certain phases of jury trials or trials generally, such as discovery proceedings, pre-trial proceedings, and reforms in the general administration and procedural aspects of jury trials. But very little lias been done in the field of jury instructions. In this panel we will not discuss the substantive law of instructions, i.e., the proper content of instructions, but rather we are going to talk about the procedural problems of instructions.

Among the problems to be considered is when the lawyers should be informed of the instructions that are to be given by the court. Section 607(a) of the Code of Civil Procedure ${ }^{1}$ provides that, upon request, the judge before argument shall inform counsel of the instructions lie intends to give. Upon inquiry I find that approximately half the judges never dis-

${ }^{1}$ CaI. Code Crv. Proc. $\$ 607$ (a): ".... Before the commencement of the argument, the court, on request of counsel, must: . . . (3) advise counsel of all instructions to be given." 
cuss instructions with counsel prior to argument, and counsel are not requesting that the judge do so. Under rule 51 of the Federal Rules of Civil Procedure, ${ }^{2}$ it is mandatory that the judge discuss with counsel prior to oral argument the instructions that he is going to give. What improvements, if any, can be made in this field? Should the basic instructions be gone over with counsel either at the time of pre-trial or prior to the swearing of the first witness? Should the judge instruct during the trial at opportune moments where questions come up that require instructions, or are section 607 (a) and rule 51 adequate?

Another problem to be considered is the question of standardized instructions. Considerable controversy has developed over the use of $B A J I .^{3}$ Should $B A J I$ be required or should it be used at all? Should we do as many judges in Los Angeles do and permit counsel simply to designate instructions by the $B A J I$ number and not even require that the instructions be typed up? Is there a better method of standardizing instructions? Also in connection with instructions, there is the very difficult question of the right and duty of a trial judge to comment on the evidence either in civil or criminal cases. Another question is whether instructions should go into the jury room in civil cases. They are by statute permitted to go into the jury room in criminal cases. ${ }^{4}$

This, generally, is what we are going to discuss. I will call upon each member of the panel to give his views on these various subjects, and then the members of the panel will ask each other questions, and the last part of the discussion will consist of answering questions from the floor. The order in which we are going to speak is trial lawyer, trial judge, professor, and appellate judge. The first man is Ray Robinson, one of the outstanding trial lawyers in the State of California.

MR. ROBINSON: I firmly believe that one of the most important, if not the most important, aspect of a successful jury trial is the proper preparation of instructions. Furthermore, so far as my experience is concerned, the submission of an abstract instruction from $B A J I$, rather than a personalized instruction, is simply a demal of a competent jury trial. This view has not been arrived at hurriedly or without testing in the courtroom before juries. Clearly, for the conduct of a proper trial, you must have adequate preparation of facts and adequate preparation of law, and you must also

2 FED. R. CIv. P. 51: "At the close of the evidence or at such earlier time during the trial as the court reasonably directs, any party may file written requests that the court instruct the jury on the law as set forth in the requests. The court shall inform counsel of its proposed action upon the requests prior to their arguments to the jury, but the court slall imstruct the jury after the arguments are completed."

3 Palaier, Californta JURy Instructions-Civil (sometimes called Book of Approved Jury Instructions-BAJI) (4th rev. ed. 1956).

4 CAL. Pen. CODE § 1137. 
have adequate preparation of instructions in order to present the facts and the law to the jury. Obviously a proper instruction should be framed in terms of the factual issue so that the jury knows what you are talking about, just as a proper instruction should embody the legal issue. Otherwise the instruction becomes meaningless. The purpose in using some form of standardized instructions is theoretically good. But such instructions should be tested or evaluated on the basis of whether they assist the jury in arriving at an equitable result, rather than whether they save time for attorneys and judges.

A controversial practice I have used in trying innumerable cases is interrogating the jury on voir dire as to whether they have any prejudice against an instruction and whether if the court gave such an instruction, they would abide by it. In my opinion this alerts the jury in advance to both the factual and legal issues. And after all there is no reason to expect the jury to arrive at a just result in a complete vacuwn, not knowing what the case is all about, especially if they are thrown a series of abstract instructions that would apply to any given case.

As to when the judge should inform the attorneys of the instructions he intends to give, I feel this should be as early as possible in the trial. The first step toward achieving this would be to require submission of basic instructions prior to pre-trial, and by basic, I mean the particularized important instructions of a case. If possible these instructions should be agreed upon at that time; if not, the judge will at least know the views of counsel. This should enable the trial judge to determine the theory of the case and the theory of the law and allow him to promulgate the instructions to the attorneys prior to the impaneling of the jury. Of course, I realize that the judge cannot know whether he will give certain instructions until all the evidence is in. But with utilization of modern discovery procedures and a crystallization of both legal and factual thinking regarding the case before swearing the jury, this problenı can be minimized. Furthermore, the judge can very well provide that if an attorney presents certain evidence, the instructions will be given.

In addition to informing the attorneys of the instructions to be given, I believe the judge should present two or three or perhaps even eight or ten basic instructions to the jury before any testimony is taken, telling them that these instructions will necessarily have a factual aspect to them. Let the jury know what the issues are and where they are going. If the court will give the basic instructions to the jury at this time and if the opening statements are given sufficient latitude so that each side can amplify those instructions, the jury can start out on the case in an informed and intelligent manner and is in a position to evaluate and put in the proper pigeonhole the testimony of the witnesses. Without question, I know that jury instructions 
are of vital importance to the successful presentation of a case to the jury, and I know that juries pay attention to them. But I suspect that many judges find that juries frequently come back and ask to have instructions reread to them. I am convinced that this is a by-product of formal instructions and of a failure to forewarn the jury as to the issues and the law applicable thereto. As a result the jurors come back and ask for several given instructions, which actually can present an erroneous picture, because they are likely to return a verdict based on the repeated instructions rather than on a consideration of the complete instructions.

JUDGE SWEIGERT: I would like to first consider the tools which trial judges liave to aid them in instructing juries. I would say that these tools consist of a few statutes, which are very vague; the $B A J I$, which is the most valuable tool of the trial judge; and finally such instructions as are prepared by the attorneys in the case and submitted to the judge.

As far as I can tell from the statutes, the trial judge is not bound to instruct the jury at all in civil trials. ${ }^{5}$ Section 608 of the Code of Civil Procedure ${ }^{6}$ says he may state all matters of law on which he thinks it necessary to instruct the jury. Section $609^{7}$ provides that if special instructions are requested, the court must give such instructions or refuse or give them with modification, so that it may distinctly appear what instructions were given in whole or in part. Section $607(a)^{8}$ makes it the duty of counsel to

The constitutional provision regarding instructing the jury is also permissive. CaL. CoNsT. art. VI, § 19 provides: "The court may instruct the jury regarding the law applicable to the facts of the case, and may make such comment on the evidence and the testimony and credibility of any witness as in its opinion is necessary for the proper determination of the case. The court shall inform the jury in all cases that the jurors are the exclusive judges of all questions of fact submitted to them and of the credibility of the witnesses."

6 CaI. Code Crv. Proc. $\$ 608$ : "In charging the jury the court may state to thein all matters of law which it thinks necessary for their information in giving their verdict; and if it state the testimony of the case, it must inform the jury that they are the exclusive judges of all questions of fact."

7 CAL. Code CIv. Proc. $\$ 609$ : "Where either party asks special instructions to be given to the jury, the court must either give such instruction, as requested, or refuse to do so, or give the instruction with a modification, in such manner that it may distinctly appear what instructions were given in whole or in part."

${ }^{8}$ CAI. CODE CIv. Proc. $\$ 607$ (a): "In every case which is being tried before the court with a jury, it shall be the duty of counsel for the respective parties, before the first witness is sworn, to deliver to the judge presiding at the trial, and serve upon opposing counsel, all proposed instructions to the jury covering the law as disclosed by the pleadings. Thereafter, and before the commencement of the argument, counsel may deliver to such judge, and serve upon opposing counsel, additional proposed instructions to the jury upon questions of law developed by the evidence and not disclosed by the pleadings.... Before the commencement of the argument, the court, on request of counsel, must: (1) decide whether to give, refuse or modify the proposed instructions; (2) decide which instructions shall be given in addition to those proposed, if any; and (3) advise counsel of all mstructions to be given. However, if, during the argument, issues are raised which have not been covered by instructions given or refused, the court may, on request of counsel, give additional instructions on the subject matter thereof." 
deliver all proposed instructions to the court and to serve them on opposing counsel before the first witness is sworn; under recent amendment, the court must decide before argument whether to give, refuse or modify the proposed instructions, and also what additional instructions to give. Further, the court has the duty of advising counsel of all instructions to be given. The only other statute dealing with instructions in a civil trial is section 2061 of the Code of Civil Procedure ${ }^{\theta}$ which provides that the court on all proper occasions must instruct a jury on seven basic matters relating to evaluating and weighing the evidence. This is about all the California law that I know of with respect to instructions in civil trials.

On the criminal side the situation is a little different. ${ }^{10}$ Among other things, it is provided that the jury may take into the jury room any written

${ }^{9}$ CAL. Code Crv. Proc. $\S 2061$ : "The jury, subject to the control of the court, in the cases specified in this code, are the judges of the effect or value of evidence addressed to them, except when it is declared to be conclusive. They are, however, to be instructed by the court on all proper occasions: 1 . That their power of judging of the effect of evidence is not arbitrary, but to be exercised with legal discretion, and in subordination to the rules of evidence; 2 . That they are not bound to decide in conformity with the declarations of any number of witnesses, which do not produce conviction in their minds, against a less number or against a presumption or other evidence satisfying their minds; 3 . That a witness false in one part of his testimony is to be distrusted in others; 4 . That the testimony of an accomplice ought to be viewed with distrust, and the evidence of the oral admissions of a party with caution; 5 . That in civil cases the affirmative of the issue must be proved, and when the evidence is contradictory the decision inust be made according to the preponderance of evidence; that in criminal cases guilt must be estabhished beyond reasonable doubt; 6 . That evidence is to be estimated not only by its own intrinsic weight, but also according to the evidence which it is in the power of one side to produce and of the other to contradict; and, therefore, 7 . That if weaker and less satisfactory evidence is offered, when it appears that stronger and more satisfactory was within the power of the party, the evidence offered should be viewed with distrust."

10 Basic statutes concerning instructions in criminal trials are:

CAT. PEN. CODE $\$ 1093$ : "The jury having been impaneled and sworn, the trial inust proceed in the following order, unless otherwise directed by the court: ...6. The judge may then charge the jury, and must do so on any points of law pertinent to the issue, if requested by either party; ... At the beginning of the trial or from time to time during the trial, and without any request from either party, the trial judge may give the jury such instructions on the law apphicable to the case as he may deem necessary for their guidance on hearing the case. ..."

CAX. PEN. CODE $\$ 1093.5$ : "In any criminal case which is being tried before the court with a jury, all requests for instructions on points of law must be made to the court and all proposed instructions must be delivered to the court before commencement of argument. Before the commencement of the argument, the court, on request of counsel, must: (1) decide whether to give, refuse, or modify the proposed instructions; (2) decide which instructions shall be given in addition to those proposed, if any; and (3) advise counsel of all instructions to be given. However, if, during the argument, issues are raised which have not been covered by instructions given or refused, the court may, on request of counsel, give additional instructions on the subject matters thereof."

CAL. PEN. CODE $\$ 1127:$ ".... In charging the jury the court may instruct the jury regarding the law applicable to the facts of the case, and may make such comment on the evidence and the testimony and credibility of any witness as in its opinion is necessary for the proper determination of the case .... Either party may present to the court any written charge on the law, but not with respect to matters of fact, and request that it be given. If the court thinks it correct 
instructions that the court has given ${ }^{11}$ it is doubtful if this can be done in civil trials.

It seems to me that judges, in handling instructions, fall into one of three categories. First, there are those who prefer to depend on what is. submitted to thein by the attorneys. I am told that some judges simply take the instructions presented by both sides, go over them a little bit and then read these instructions from both sides to the jury, sometimes without much attempt to even rearrange them. The second type of judge depends on the attorneys to initiate the instructions but spends hours editing thein and then reads both sets of instructions subject to whatever work he has done in going over them. The third type of judge prefers not to depend upon the attorneys, even for originating the instructions. This judge has probably taken $B A J I$ as a base and at considerable effort and over a long period formed a set of his own jury instructions, which he feels will be adequate, with minor adjustments, for 75 per cent of the cases he hears. This judge will not not be interested particularly in having the attorneys present instructions. He will, of course, go over those instructions presented to determine the subject matters of the requests, what special instructions are necessary, and what statutes and special rules are involved; he then checks to see whether he has covered thein in his instructions.

I do not know which of these practices prevails in this State. Personally, I prefer not to depend on the attorneys for the origination of instructions. At the outset of trial I will call the attorneys in and go over the case in a preliminary conference and seek to find out from them what particular subjects or points of law might well be involved in the case. I tell thein that any special instructions should be prepared for submission to ine. As to other instructions, I tell thein that I will give the instructions which I think necessary, and that they need not concern themselves with them.

As to the use of $B A J I$, I would like to refer to a 1956 report of the State Conferences of Judges, ${ }^{12}$ which, while recognizing that the $B A J I$ has relieved judges from a great deal of tedious and careful checking of proposed instructions, pointed out that these handbooks were not designed by the editors as a set of ready-made instructions. It said that these handbooks contained instructions on various subjects and that each one was

and pertinent, it must be given; if not, it must be refused. Upon each charge presented and given or refused, the court must endorse and sign its decision and a statement showing which party requested it. If part be given and part refused, the court must distinguish, showing by the endorsement what part of the charge was given and what part refused."

See also CAL. PEN. CODE $\S \S 1096,1096$ (a) (instructions regarding presumptions of innocence and reasonable doubt); $\S 1127$ (b) (instruction regarding expert testimony); and $\S 1127$ (c) (instruction regarding evidence of flight of accused).

11 Cal. Pen. Code § 1137.

12 Conference of Carmornia Judges, Report of Commattee on Strertor Courts, Standardization OF JURY Instructions (1956). 
fairly complete upon its separate subject matter, but that the editors left a great deal to the resourcefulness of the individual judge in molding these separate instructions into a proper and adequate set of instructions for each individual case. There has been much complaint about the practice of giving a jury $B A J I$ instructions in the abstract, frequently by just reading them out of the book. I think it is far better to use the $B A J I$ instructions as a basis for the court's own instructions and to give them life by making reference to the names of the parties and the mstrumentality involved so that the instructions lose some of their abstractness and can be readily applied to the particular case. I do not mean that the judge should pick up a lot of formula instructions handed in by the attorneys. I think that if a judge works out his own set of instructions, using $E A J I$ as a basis, he will have adequate opportunity to state the issues in a personalized way to the jurors. I think, from my own experience, that a set of instructions can be developed that will, for all practical purposes, serve you in 75 or 80 per cent of the cases that come before you.

The above inentioned report went on to suggest that perhaps the time has come to consider a step beyond $B A J I$, by working out for the judges of the State in possible collaboration with the editors of $B A J I$ or with the Judge's Conference or the universities, a suggested set of instructions for, let us say, negligence cases. A report from the same committee in $1957^{13}$ recognized that the suggestion had been made but concluded that such a second step was not presently desirable because more work was being done on $B A J I$ in an attempt to simplify and improve it in Los Angeles County. The only suggestion inade by the committee was that for the present the various counties should adopt the system used in Los Angeles County of eliminating preparation of a lot of instructions and having instructions requested according to the $E A J I$ type.

FROM THE FLOOR: The State Junior Bar Association has a project underway for the simplification of instructions, and it may be that some of the judges here have received copies of proposed instructions. At this point they are limited to negligence cases, and they attempt to simplify the language of $B A J I$.

PROF. LOUISELL: I have not had any experience in California in the trial of jury cases, and I realize that my observations are not those of one who has participated in the process here. But based on my experience in other jurisdictions, and ny observations here as well as elsewhere, I feel that the weakest part in the conduct of jury trials in California, concerns

13 Conference of Calmorna Judges, Report of Committee on Supertor Courts, STANDARDIZATION OF JURY INSTRUCTIONS (1957). 
the manner of instructing the jury. I would like to tell you what I regard as the ideal in instructing a jury. Let me take, for example, the case of a judge in the District of Columbia who was on the bench for many years. He was appointed, I think, by President Woodrow Wilson and was still trying cases, although on retirement, at least as recently as 1953 or 1954. The type of instruction he would give to a jury can best be characterized, I think, essentially as talking with the jury. I've even seen him leave the judge's bench and go down and sit in the witness chair apparently in order to be closer to the jury. He would converse with the jury and was usually quite brief in the ordinary case, for example, the typical negligence case. He seemed to be in real command of the evidence; he would marshal the evidence briefly but objectively and fairly: "Members of the jury, this is what the plaintiff claims." Then the cogent factors in support of the plaintiff's claim would be summarized. Similarly, he would sum up the significant items of the evidence in favor of the defendant. As he was doing this, he would integrate into his presentation the controlling legal principles, but without abstractions or long verbal formalizations that, so it seeins to me, often require almost the ability of gerius to follow. When he was through, he would suggest to counsel without imputation that there was any impropriety in their coming forward, "Now, gentlemen, what have I forgotten to tell the jury? If I've forgotten anything important, come up here and remind me of it." As the occasion demanded, he would then go into further matters that he had overlooked.

For the last 30 years or more there has been much talk about cominent on the evidence, and how far the right should be exercised in jurisdictions where comment is authorized. While good, fair, objective coinment by experienced trial judges can be a significantly helpful thing, the right of comment in my opinion is not at the heart of this problem of informing and instructing the jury. The real answer lies in marshalling the evidence and directly and clearly applying to it the applicable legal principles. Abstract concepts about what is or is not proximate cause, when realistically no proximate cause issue is raised by the evidence, are certainly of little value to a jury. I realize that a trial judge must be aware of the realities of appellate review of a written record, but I feel that appellate court requirements can be satisfied without resorting to abstract instructions, frequently of great complexity and prolixity. The trial judge should be able to tell the jury in understandable lay langnage the issues as he sees them. This is what I call marshalling the evidence fairly and integrating with the evidence the controlling legal principle.

JUSTICE PETERS: Corroborating what has already been said, I have observed, in reading transcripts over the past 25 or 30 years, that there is 
more and more a tendency on the part of trial judges to use $B A J I$ or some other form of standardized abstract instructions. This is probably partly due to the overemphasis that is now being made on speeding up trials. Speed is important, but there must be a balance between the quality and speed of a trial. Of course, the easiest thing for a judge to do is to read his instructions right out of $B A J I$, and this is a reasonably safe method of procedure, though not invariably safe. The appellate courts have reversed a substantial number of cases predicated upon use of some of the $B A J I$ instructions. I agree with Ray Robinson and Judge Sweigert that the instructions should be tailored to fit the particular case so the jury knows what the judge is talking about, and I was very interested in what Professor Louisell said about marshalling the facts and commenting on the evidence. The first case before the California appellate courts ${ }^{14}$ regarding the constitutional provision permitting comment on the evidence ${ }^{15}$ arose when the judge said after instructing the jury, "Now I am permitted to comment upon the evidence, and I am now going to comment on the evidence. You've heard the argument of the district attorney. I beheve everything he said; now, go out and do your duty." Of course, that was neither comment nor marshalling the facts, and it obviously resulted in a reversal. It is extremely difficult in this State, where there are about 375 trial judges, to lay down a rule on commenting on the evidence that can fit the qualities of so many different people.

A problem that has bothered ine ever since I was first appointed to the district court of appeal in 1939 is the tendency in personal injury cases to make the instructions on basic concepts, that is, on proximate cause, contributory negligence, res ipsa loquitur, last clear chance, preponderance of evidence, etc. too personalized. The plamtiff's lawyer takes the basic instruction and puts in a few adjectives or adverbs to help his side of the case and the defendant's counsel does the same thing for his side. The result is that the time and efforts of the appellate court are unreasonably taken up in passing on the propriety of instructions on basic concepts. How can this be avoided? I think the Penal Code suggests a solution. Section 1096 defines presumption of innocence and reasonable doubt. Section 1096(a) provides that in charging a jury the court may read section 1096 to the jury, and that no further instruction on the subject of presumption of innocence or reasonable doubt need be given. It occurs to me that we might take a leaf out of the criminal law book and apply it to civil cases. Prior to the passage of section 1096, practically every criminal case discussed at length the instructions on presumption of innocence and proof beyond a reasonable doubt. Since the passage of section 1096, you will find that there

14 People v. Talkington, 8 Cal. App. 2d 75, 47 P.2d 368 (1935).

16 CaI. Const. art. VI, § 19. 
is hardly a case that discusses these instructions. This section contains only a very abstract statement of these two basic concepts. Something similar could be done in the field of civil cases. Why shouldn't the legislature draft, with the assistance of the State Bar, the Conference of Califorma Judges and the Judicial Council, if necessary, instructions on negligence, contributory negligence, proximate cause, res ipsa loquitur, last clear chance, proof beyond a reasonable doubt, and perhaps the basic instructions on damages. It could be provided that these would not necessarily be completely abstract statements of law. There could at least be left in the form of such instructions the blanks for the insertion of the names of the parties and of the instrumentality involved. Other ways of personalizing the instructions may occur to you. This seeins to ine a matter of really vital importance as far as the time of the appellate courts is concerned.

The importance of informing the attorneys as soon as possible of the basic instructions to be given, perhaps even as early as pre-trial, has already been discussed. Even more inportant to me than this question is that of when the jury should first be told about the principles of law involved. I know a trial judge who has been trying a very interesting experiment. $\mathrm{He}$ is doing it by stipulation of cousel because he feels that otherwise there might be possibility of error, and he is receiving the hearty cooperation of most of the lawyers in his community. Before the first witness is sworn, he instructs the jury generally on the law. And I do not mean just generally telling thein about the case and what issues are involved as many of you undoubtedly do. He does that, but he also specifically instructs thein on negligence and contributory negligence and the basic issues that will obviously be involved in the case. He has not been doing this long enough to make any real appraisal of whether it's better to wait until after the close of argument to instruct, but his tentative view is that this is of great benefit and that the jury appreciates it. It is certainly true that particularly in the so-called cow counties inost of the people have not served on juries before. And you have all heard the complaint made by jurors that, "I didn't know what that case was about, or what I was supposed to do until it was half over." It seems to me that in any scientific approach to the intelligent determination of a factual issue according to principles of law the jury should know as early as possible the principles of law that are binding on them in ascertaining the facts.

I wonder if Judge Nourse, who is in the audience, could explain how $B A J I$ is used in Los Angeles County, and also, since he is on the committee that is drafting the $B A J I$ imstructions, tell how they are drafted.

JUDGE NOURSE: In using $B A J I$ in Los Angeles, each clerk in the trial department is furnished with an entire set of $B A J I$ instructions, retyped 
and set out in looseleaf. These are furnished free, being paid for by the royalties that the $B A J I$ committee gets from the West Publishing Company. When the attorneys hand in their lists of desired $B A J I$ instructions, the clerk marks on each instruction which party or both have requested it. Then, all requested instructions are handed to the judge as separate looseleaf instructions.

I have been on the $B A J I$ committee from its mception in the late twenties. Judge Palmer was then the chairman of the committee, and there were five trial lawyers and three judges. The committee is now formed of four judges and four trial lawyers and meets once a week to simplify $B A J I$ and to revise some of the instructions that the Supreme Court has criticized. Each time there is a change, the new form of the instruction is sent out to the judges, and the bar is notified as soon as possible through the West Publishing Company's supplements, which come out at least once a year.

JUSTICE PETERS: Judge Sweigert, when do you think the jury should first be instructed on fundamentals?

JUDGE SWEIGERT: I think the best practice would be for the judge to clearly state the issues to the jury and tell them what they will be called upon to decide. This can be done after the opening statements have been made and before the witnesses are called. In stating the issues, the court can explain such terms as negligence, proximate cause, and contributory negligence. In other words, just give certain basic instructions in advance to orient the jurors so that they can follow the testimony intelligently. I do this to a limited extent. I even give some of the instructions on voir dire, e.g., those relating to the duties of a juror. Before the case starts, I give them an instruction on the issues, simply stating that the plaintiff alleges that the defendant was negligent and that as a result of that negligence, certain events happened which caused injury to plaintiff for which he seeks damages. I enumerate the issues which the jury will be required to decide. In many cases I give them at this time the basic definitions of "negligence," "contributory neghigence" and sometimes "proximate cause," although I am usually afraid of frightening them with that instruction. I state that these instructions are preliminary and that further instructions will be given at the proper time. Sometimes, after discussion with the attorneys, I even instruct the jury on the law before the arguments.

PROF. LOUISELL: Judge Nourse told me that it was his customary practice to instruct before argument of counsel but that he would reserve a few of the general instructions until after counsel had argued in order that he would be the last one to address the jury. But the bulk of his instructions, 
as I understood it, were given before argument of counsel. Now I think this is relatively unusual in the United States, and I wonder if there is not a real opportunity here to improve the quality of argument.

JUDGE SWEIGERT: I think it is a good idea to repeat any instructions given before the arguments in the final instructions. This way they are reimpressed on the jury and fully tied in with the other instructions.

JUSTICE PETERS: I should think there would be no difficulty at all in instructing at any time, providing the judge also fully instructs at the close of the case. Otherwise, there might be a possibility of error. Section 607 of the Code of Civil Procedure sets forth the various steps of a trial and provides that after argument the court may charge the jury. However, this provision is qualified by the statement that the court for special reasons may otherwise direct the order of trial.

We have been talking about the $B A J I$ instructions a great deal. I wondered, Mr. Robinson, if aside from your criticism that the $B A J I$ instructions were too abstract, you have any other basic objections to $B A J I$.

MR. ROBINSON: I think that any attorney who has represented both plaintiff and defense sides of personal injury cases, for example, could not help concluding that the original $B A J I$ instructions were loaded in favor of the defense. This is not only the view of 99 out of 100 attorneys who have tried plaintiff's cases but also of a number of appellate and superior court judges as well. I think an honest and constructive effort has been made to try to correct that. When Judge Nourse said they had some attorneys and judges working currently on this problem I wondered as to the balance of those attorneys with respect to representing plaintiff's and defendant's viewpoints.

JUDGE NOURSE: They are chosen from both branches of advocacy.

MR. ROBINSON: They might supplement the $B A J I$ committee with some professors, $I$ think, and some members of the Conference of Judges. In view of the tremendous influence of $B A J I$, I think it is essential that the committee be as impartial as possible.

PROF. LOUISELL: I hike to think of $B A J I$ as an excellent form book. When it is used as such, it can, like any good form book, perform a tremendous time-saving function. The trouble is, as with form books in general, that there is the tendency to use it blindly without integrating its instructions with the facts of the case. That it is capable of good use, I think, is attested by its use not only in Califorma but in many other States. The whole problem is as to its proper use. 
JUDGE SWEIGERT: There is no question that $B A J I$ is an excellent service to the courts, but I think it can be overused. It still remains the duty of the judge to take the $B A J I$ instructions and edit them into a set of instructions that can be given in a particular trial. By editing, I do not mean changing the substantive statement of the law, because that has been well done in $B A J I$. But, each $B A J I$ instruction has been drawn so as to be complete in itself. As a result, a considerable part of an instruction inay be repetitive. If the judges would, when using $B A J I$ and following it as far as the substantive statement is concerned, eliminate those repetitions and also arrange the instructions so that they follow reasonably from one subject to another, a jury could better follow and understand the instructions.

I think the use of transition in instructions is extremely important. It is very helpful to a jury to indicate to them a little beforehand upon what subject you are going to instruct. For instance, befare instructing on negligence, it would be desirable to say something such as, "Now, I'm going to give you some instructions concerning the meaning of the term 'negligence' and 'contributory negligence." "

It is also desirable if the judge, using $B A J I$ as a base, can work up his own instructions and then put them to his own memory. It then becomes unnecessary to have a lot of written instructions in front of him. The judge can turn to the jury with only a few notes and give due emphasis so that the jurors will feel that they are being orally instructed. This can easily be done. A jury will listen more attentively if the judge leads them along from subject to subject and does not use too much legal language. Get some ordinary language in there, mention names, and use only such legal language as is absolutely essential to state the rnle of law. For instance, you might say, "Now, I'm going to give you some instructions on the duty of John Jones, who at the time of this event was working inside the house. Such a person as that is called an invitee. And the duty of the owner towards a person of that kind on his premises is as follows." Then you can work in the legal language very well. In general; offset the legal verbiage with enough common, ordinary language to establish a contact between the judge and the juror. Now, I do not mean by this that the judge should give formula instructions. I simply mean that instructions on rules of law have to be related to time, place and persons, and they have to be given in a sufficiently orderly manner to enable the jury to understand them. The mere reading of instructions is not enough.

JUSTICE PETERS: I would like to see if we have any more comments from the panel about the problem of commenting on the evidence. From what I have observed in transcripts, very few judges at the superior court level, comment in either criminal or civil cases. In the few cases that I have 
observed in which comment has been made, it has usually been where the judge felt very strongly about a matter and it was very difficult for him to keep his convictions out of his so-called objective comment. Mr. Robimson feels that it emasculates the jury system to permit comment on the evidence. Professor Louisell advocated a reasonable approach on comment on the evidence. Judge Sweigert, how do you feel on this? Do you comment on the evidence?

JUDGE SWEIGERT: I have done it in one or two criminal trials and in some civil trials. Generally, however, it is unnecessary and, secondly, it is not often advisable to inject your own private opimion of the evidence into the case. I do think, however, that a judge on a proper occasion, where he feels in his conscience obliged to do it, should not hesitate to make a wellconsidered judicial comment on the evidence.

MR. ROBINSON: The position of the competent trial judge with a jury is bound to be one of great influence. His words and observations in the normal case are accepted by the jury as being very important. Thus, any comment from the judge to the jury is accepted by them almost as a direction. I feel that the first evaluation of the evidence should be made by the jury under proper instructions and with the usual safeguards accorded in the introduction of evidence. Then, if the judge feels that there has been a miscarriage of justice, because the factors which had originally caused him to want to comment on the evidence have been ignored, he has the legal right to set the verdict aside.

The further problem, of course, of commenting on the evidence is the danger of there being reversible error. When you say "proper judicial comment," I am not prepared to know what it would be. I have never liad a judge comment on the evidence in any case that I lave tried. This right seems to have been used very sparingly, whicl, so far as I am concerned, is a move in the riglit direction.

PROF. LOUISELL: I think that quite a sharp distinction should be drawn between the process of marshalling the evidence, which I spoke of earlier, and that of deliberately commenting in such a way as to express an opinion on the credibility of witnesses and evidence. I agree that the occasions for strong comments on the evidence are relatively rare. In a fairly recent California case, Pomerantz v. Bryan Motors, Inc., ${ }^{16}$ the court upleld the strong comment of the judge that either plaintiff or the defendant's agent was lying. The judge did not say which one he thought was lying, but he put it in very strong terms. He made it clear that it was not a 
question of mistake. On the other hand, in a federal court where the right of comment is reputedly so uninhibited, a trial judge was reversed because he said one witness or the other was lying and then he more or less indicated which one it was. This talk about the federal courts being so free and easy on comment, I think, has to be taken with a grain of salt. The case is Virginia Ry. v. Armentrout. ${ }^{17}$

QUESTION: Professor Louisell, in the use of your idea of marshalling the evidence, it seems to me the judge faces a very difficult problem in any case of having to be selective in what he marshals. If he attempts to summarize every witness' testimony, he will be giving a very long and intricate explanation. If he is selective, there is the danger that he will give undue emphasis to something.

PROF. LOUISELL: That is very true. In fact, I think marshalling the evidence is the hardest part of charging the jury. That is why it should be accompanied with the caution to the jury that no attempt has been made to summarize all the evidence, that the jury is the final judge of the evidence, and that they may and will recall other items of evidence not included in the judge's summary. I thoroughly agree this is a hard thing to do, but I think the danger involved is outweighed by the advantages.

JUSTICE PETERS: This must present quite a problem with a case that takes 2 or 3 weeks or a month to try. There is always the grave danger, even in a simple case, that the trial judge in marshalling the evidence, while not expressing any opinion about the evidence, will put such emphasis in the minds of the jury upon certain facts that he will, by not mentioning other facts, mislead the jury. I ain not sure that there is not more danger of having a case reversed, or what is much more important, more danger of a miscarriage of justice, if the judge is permitted to place emphasis on certain facts. It takes a remarkably competent judge to be able to marshal the evidence objectively, when he has no transcript before him and can not look back at what happened 3 days or 3 weeks ago and determine precisely what each witness said.

QUESTION: What does the panel think about allowing the jurors to take instructions into the jury room?

MR. ROBINSON: Of course in criminal cases, the jurors are allowed by statute to take instructions to the jury room, but in civil cases I think my present view would be that they should not take instructions with them; rather they should come back and ask for any they desire to have reread. 
Even then, $I$ think there is a real danger when a jury asks for a specific instruction to be reread that the case may be unjustly determined on one instruction. I think that if a specific instruction is reread, the judge should be very cautious to see that it is not given isolated significance. Probably some related instructions should be read along with it, because frequently one juror will pick out an instruction and try to sell his side of the story on that instruction.

FROM THE FLOOR: We have made extensive use of the practice of permitting instructions in criminal cases to go into the jury room at the request of the jurors. In practically every case the jury will request the instructions. It is my opinion that we arrive at much better and faster verdicts by doing so.

JUSTICE PETERS: If the judge has had an instruction offered to him which he has corrected, does he just strike out the four or five lines that he does not hike or write in his corrections in long hand with the jury taking both the crossed out material and the other?

FROM THE FLOOR: Yes. We do clip off of the proposed instructions any references as to whether they are plaintiff's or defendant's, however.

JUDGE SWEIGERT: I think it would be helpful if certain basic instructions, such as defimitions of negligence and contributory neghigence and instructions on the burden of proof, could be taken to the jury room. 